Annals of Glaciology 61985

(C) International Glaciological Society

\title{
EFFECTS OF DRIFTING SNOW ON SURFACE RADIATION BUDGET IN THE KATABATIC WIND ZONE, ANTARCTICA
}

by

Takashi Yamanouchi and Sadao Kawaguchi

National Institute of Polar Research, 9-10 Kaga 1-chome, Itabashi-ku, Tokyo, Japan 173

\section{ABSTRACT}

Effects of drifting snow are examined from measurements of radiation fluxes at Mizuho Station in the katabatic wind zone, Antarctica. A good correlation is found between the difference of downward longwave fluxes measured at two heights and wind speed used as an index of drifting snow. The wind increases the downward flux at a rate of $2 \mathrm{~W} \mathrm{~m}^{-2} / \mathrm{m} \mathrm{s}^{-1}$ when wind speed is higher than $13 \mathrm{~m} / \mathrm{s}$. Drifting snow suppresses the net longwave cooling at the surface. Direct solar radiation is depleted greatly by the drifting snow; however, the global flux decreases only slightly, compensated by the large increase of the diffuse flux, at a rate of about $1 \%$ for each $1 \mathrm{~m} / \mathrm{s}$ increase in wind speed. At Mizuho Station, the effect on longwave radiation prevails throughout the year. The relation between snow drift content and wind speed is obtained from shortwave optical depth measurements as a function of wind speed. A simple parameterization of radiative properties is given.

\section{INTRODUCTION}

Drifting snow is of ten seen on the slope of the Antarctic continent where katabatic winds prevail. The drifting snow is not only important to mass balance of the ice sheet, but also affects heat balance of the snow surface partly through the radiative process.

Many studies have been made on snow drift transport relating to the turbulent transfer in the surface layer. However, only a few are concerned with the effect of drifting snow on the radiation budget. Kawaguchi (1979) pointed out that drifting snow has a strong effect on the surface radiation budget in the katabatic wind region. Light scattering by drifting snow particles was discussed using visibility data by Mellor (1966), Kobayashi and Makino (1975), Schmidt (1979) and Tabler (1979); however, discussions did not extend to the radiation budget.

Here effects of drifting snow on the radiation budget are presented from measurements at Mizuho Station $\left(70^{\circ} 42^{\prime} \mathrm{S}, 44^{\circ} 20^{\prime} \mathrm{E}\right)$, Antarctica. Climate of the station is characterized by continuously blowing katabatic winds; in the six winter months the average wind speed is more than $10 \mathrm{~m} / \mathrm{s}$, and more than two thirds of days have drifting snow. Radiation measurements at Mizuho were made under the Japanese POLEX-South program in 1979-1981.

\section{MEASUREMENTS}

Since drifting snow particles lie in the lower layer near the surface, measurements of radiation fluxes were made at two heights: one set of upfacing and downfacing pyrogeometers (Epply PIR: $4-50 \mu \mathrm{m}$ ) and pyranometers (Eko MS-800: $0.3-2.8 \mu \mathrm{m}$ ) was mounted at $1.5 \mathrm{~m}$ at $30 \mathrm{~m}$. Direct solar radiation was measured by a pyrheliometer $(0.3-2.8 \mu \mathrm{m})$ mounted at $1.5 \mathrm{~m}$. Details of measurements and calibrations are reported elsewhere (Yamanouchi and others 1981). Experimental uncertainties were estimated to about $\pm 1 \mathrm{~W} / \mathrm{m}^{2}$ for daily mean longwave fluxes, about $1 \%$ for the 30 minutes mean of direct solar radiation and \pm 1 to $3 \%$ for the 30 minutes mean of global radiation.

\section{RADIATION AND WIND SPEED}

Effect of drifting snow is examined using wind speed as an index of drifting snow: on average, drifting snow amount or density correlates to wind speed (Budd and others 1966; Kobayashi and others 1983). Figure 1 shows a good correlation between wind speed and
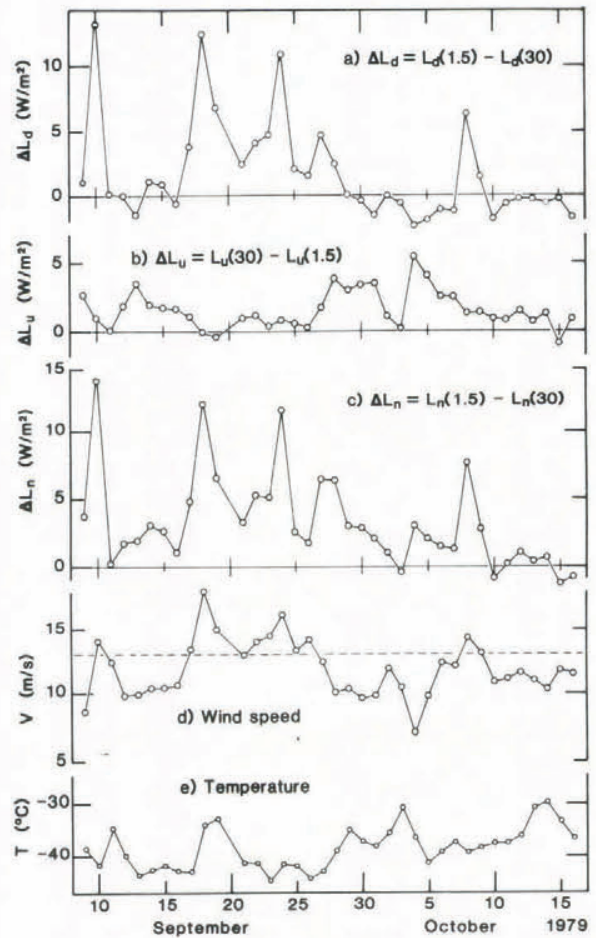

Fig.1. Difference of (a) downward, (b) upward and (c) net longwave radiation fluxes between 1.5 and $30 \mathrm{~m}$ heights with (d) wind speed ( $8 \mathrm{~m}$ height) and (e) air temperature $(1.5 \mathrm{~m})$. Daily means for Spetember and October 1979 at Mizuho Station.

difference $\left(\Delta L_{d}\right)$ of downward longwave fluxes measured at two heights (correlation coefficient is 0.81 ). This difference is clearly due to the drifting snow: correlations with other meteorological parameters such as temperature or inversion strength are poor. Drifting snow particles in the layer between 1.5 and $30 \mathrm{~m}$ increase emissivity of the atmosphere and downward flux at $1.5 \mathrm{~m}$. Considering the experimental uncertainties, the difference in fluxes at two heights is apparent when the wind speed is higher than $13 \mathrm{~m} / \mathrm{s}$. The wind-borne drifting snow increases downward flux at a rate of about $2 \mathrm{~W} \mathrm{~m}$-2/ $\mathrm{m} \mathrm{s}^{-1}$.

As for the upward radiation, the difference of fluxes measured at two heights shows only a vague correlation with the wind speed. This is because upward radiation from the snow surface is approximately equal 
to black body radiation for the surface temperature, so that the layer of drifting snow particles cannot cause any additional change to the radiation flux. As a result, wind-borne drifting snow suppresses net longwave cooling at the surface: on the contrary, the radiative cooling of the atmospheric layer is enhanced.

As we have already pointed out (Yamanouchi and Kawaguchi 1984) the dependence of longwave radiation on wind speed differs at any point according to climatic condition. At Mizuho Station, though a strong inversion exists, the lower thirty meters above the surface are well mixed by the constant katabatic wind. Therefore an increase in wind speed does not serve to raise the surface temperature, as is the case where the wind is normally weak. Increase in wind speed does however increase the amount of drifting snow, which increases the downward flux first.

From diurnal variation on 23 November 1979, the dependence of shortwave radiation flux on wind speed is examined in Figure 2, also with the variation of $\Delta L_{d}$ Ratios of direct, global and diffuse solar flux against

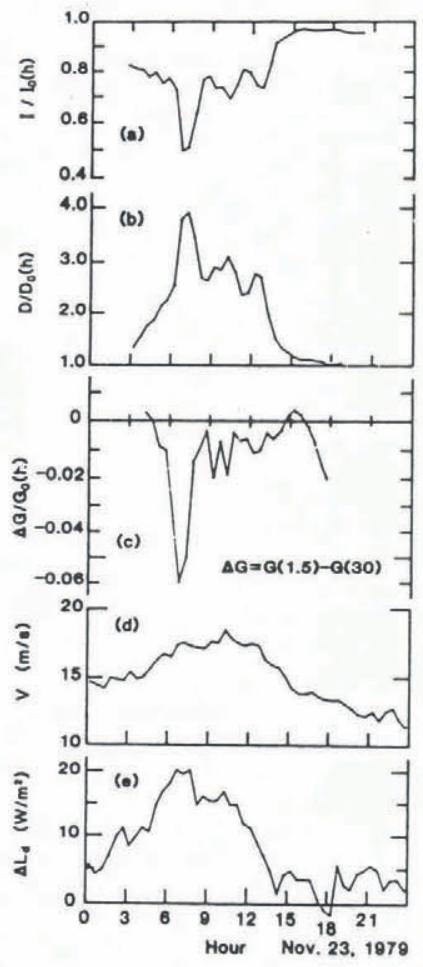

Fig.2. Diurnal variation of ratios of (a) direct, (b) diffuse and (c) difference of global solar radiation against those of the normal clear sky, (d) wind speed $(8 \mathrm{~m}$ height) and (e) difference of downward longwave fluxes at two heights (30 minute means).

those fluxes under the normal clear sky when the drifting snow above $1.5 \mathrm{~m}$ is negligible (empirical equations by Yamanouchi 1983) are shown. Direct solar radiation is depleted greatly when wind speed rises and snow drifts strongly. A large depletion up to $50 \%$ is found with wind speeds about $17 \mathrm{~m} / \mathrm{s}$. Clouds could also make such a large depletion of direct flux; however, this depletion is certainly due to the drifting snow since the difference of the downward longwave flux $\Delta \mathrm{L}_{\mathrm{d}}$ corresponds to the depletion. At the same time, the diffuse solar flux increases greatly, to about four times that of the normal amount for the maximum in the present figure. The diffuse radiation might be doubled owing to the high albedo of the surface (Yamanouchi 1983). By compensating the direct flux of depletion by the diffuse flux increase, the decrease of the global radiation by the drifting snow is small. Global radiation at $1.5 \mathrm{~m}$ height is less by about $4 \%$ than that at $30 \mathrm{~m}$ with wind speeds of $17 \mathrm{~m} / \mathrm{s}$. Since the shortwave flux

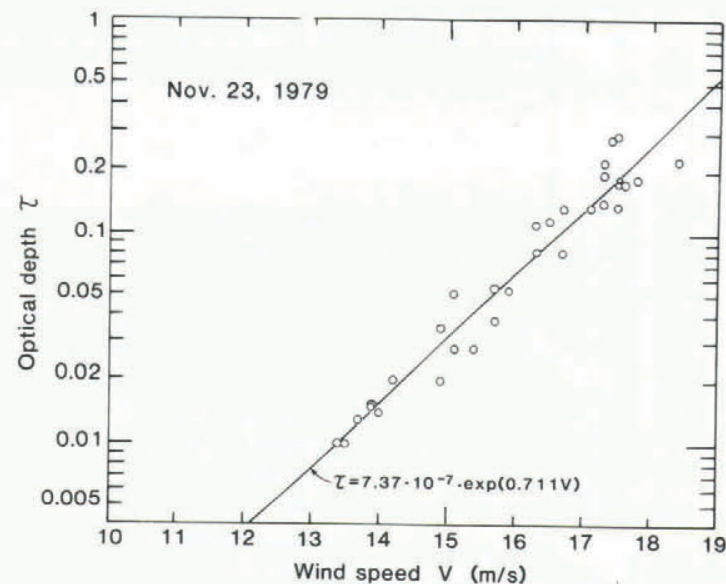

Fig.3. Optical depth of the drifting snow as a function of wind speed at $8 \mathrm{~m}$ height. Solid line is a best fit line.

depends strongly on the solar incident angle, variations cannot be determined only from the amount of drifting.

From direct solar radiation $I(h)$ the optical depth of the drifting snow above $1.5 \mathrm{~m}$ for total shortwave radiation $(0.3-2.8 \mu \mathrm{m})$ is estimated as

$$
\tau=-\frac{1}{m} \ln \left[\frac{\mathrm{I}(\mathrm{h})}{\mathrm{I}_{\mathrm{o}}(\mathrm{h})}\right]
$$

where $\mathrm{m}=1 / \sin \mathrm{h}$ is relative air mass and $\mathrm{I}_{0}(\mathrm{~h})$ is direct solar radiation at Mizuho under normal clear sky, described above for the solar elevation angle $h$. The uncertainty in deriving $\tau$ is about $\pm 10 \%$ owing to the empirical formula of $I_{0}(h)$ and wide field of view of the instrument $\left(5^{\circ}\right)$. In Figure 3 , optical depth $T$ shows a clear relation to wind speed $\mathrm{V}$ (at $8 \mathrm{~m}$ ) as

$$
T=7.3710^{-7} \exp (0.711 \mathrm{~V})
$$

\section{DRIFTING SNOW AMOUNT AND RADIATION}

Radiation fluxes are related to the drifting snow amount estimated from wind speed. Since optical depth of drifting snow is approximately proportional to the drift content, using Equation 2, the drift content $\mathrm{W}$ in a vertical column above the $1.5 \mathrm{~m}$ height can be expressed as

$$
\mathrm{W}=\mathrm{a} \exp (0.711 \mathrm{~V})
$$

where $\mathrm{a}$ is a constant.

The absolute value is tuned by the data of the visibility. From measurements by Kobayashi and others (1983), the drift density profile at Mizuho Station is approximately constant. Drift density at $2 \mathrm{~m}$ was connected to the visibility VIS $(\mathrm{m})$ by Budd and others (1966) and Kobayashi and others (1983). Then the drift density is expressed on average as

$$
\mathrm{N}(\mathrm{z})=\frac{100}{2^{-1.286} \mathrm{VIS}} \mathrm{z}^{-1.286}
$$

$\mathrm{N}(\mathrm{z})$ is integrated from $1.5 \mathrm{~m}$ to $300 \mathrm{~m}$ as an upper limit (Budd and others 1966). Since visibility was $100 \mathrm{~m}$ when the wind speed was $17.5 \mathrm{~m} / \mathrm{s}$ on the same day of Figure 3 , the constant is determined as $a=2.3410^{-5}$. The drift content between $1.5 \mathrm{~m}$ and $30 \mathrm{~m} \mathrm{~W}_{30}$ can also be estimated as

$$
\mathrm{W}_{30}=1.72 \cdot 10^{-5} \cdot \exp (0.711 \mathrm{~V})
$$

using the drift density profile Equation 4.

In Figure 4 the relation of drift content and wind speed thus obtained is compared to drift content estimated from direct measurement by other investigators. The line fitted to the data from Budd and 


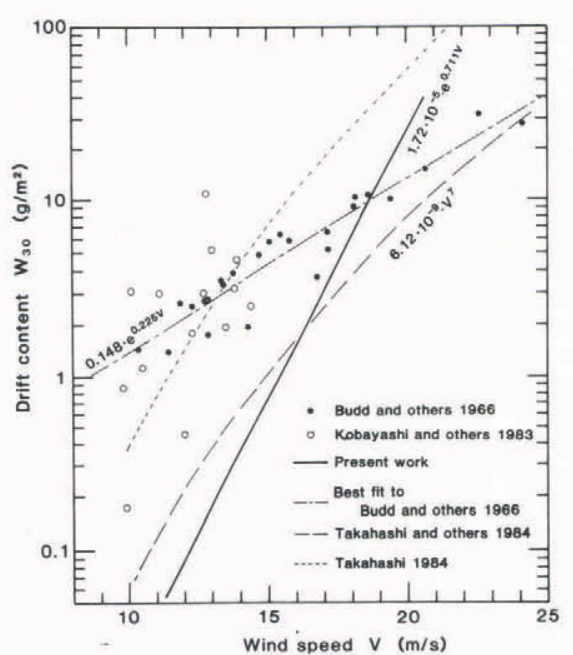

Fig.4. Drift content for 1.5 - $30 \mathrm{~m}$ layer as a function of wind speed obtained from optical depth and those estimated from values by other investigators.

others (1966) passes through the data by Kobayashi and others (1983), but has much smaller inclination than that of the present relation. The relation derived from the density at $1 \mathrm{~m}$ height by Takahashi and others (1984) for November at Mizuho Station (dashed curve) is rather similar to ours. The relation from the data by Takahashi (1985) for the whole year (dotted curve) also has a similar slope to ours, though the amount is fairly high. The relation depends on the season.

The optical depth $T$ of the drifting snow is shown as a function of drift content $W$ in Figure $5 \mathrm{a}$. Points scatter because drift content is estimated from wind speed. The best fit line shown by solid line is obtained by Equations 2 and 3, with a as

$$
\tau=0.0315 \mathrm{~W}
$$

From the relation shown by Stephens (1978) for clouds:

$$
\tau \approx \frac{3}{2 \mathrm{r}_{\mathrm{e}}} \mathrm{W}
$$

the effective radius of particles $r_{e}(\mu \mathrm{m})$ is estimated as $48 \mu \mathrm{m}$. This value is reasonable from observations of size distribution of drift snow particles in the $30 \mathrm{~m}$ layer made by Nishimura (private communication). The dashed line in Figure $5 \mathrm{a}$ is the dependence of the extinction coefficient on the drift density obtained by Mellor (1966) from visibility data reported by Budd and others (1966).
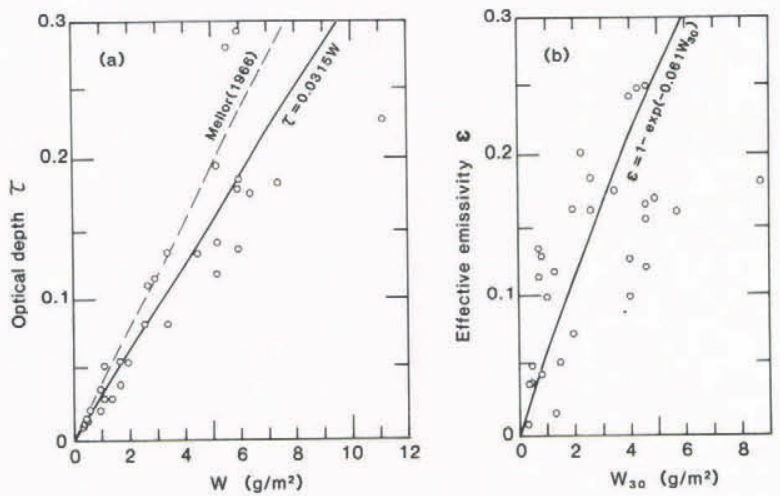

Fig.5. (a) Optical depth $\tau$ of driftin snow as a function of drift content $\mathrm{W}$ (above $1.5 \mathrm{~m}$ height). Dashed line is from extinction coefficient derived by Mellor (1966) from Budd and others (1966). (b) Downward effective emissivity $\epsilon$ of drifting snow as a function of drift content $\mathrm{W}_{30}(1.5-$ $30 \mathrm{~m}$ height). Solid lines are best-fit curves.
For the longwave flux, the effective emissivity of the layer between 1.5 and $30 \mathrm{~m}$ for the downward flux $\epsilon$ is introduced as

$$
\epsilon=\frac{L_{d}(1.5)-L_{d}(30)}{\sigma T^{4}-L_{d}(30)}
$$

as an anology of radiation properties of clouds (Stephens 1978). $\sigma \mathrm{T}^{4}$ is an blackbody radiation for the temperature $\mathrm{T}$ of the atmosphere at $1.5 \mathrm{~m}$ height with the Stefan-Boltzmann constant $\sigma$. The effective emissivity is plotted as a function of the drift content between 1.5 and $30 \mathrm{~m} \mathrm{~W}_{30}$ in Figure $5 \mathrm{~b}$. The best fit curve of the form

$$
\epsilon=1-\exp \left(-k \mathrm{~W}_{30}\right)
$$

is drawn in the figure with $k=0.061$. This value is similar to $k=0.056$ obtained by Paltridge and Platt (1981) for cirrus cloud composed of ice particles similar to drifting snow. There may be some differences in shape and size.

Without expressing the relation to $W$ explicitly, shortwave optical depth and longwave effective emissivity are plotted in Figure 6. From this, uncertainties between the relation of drift content and

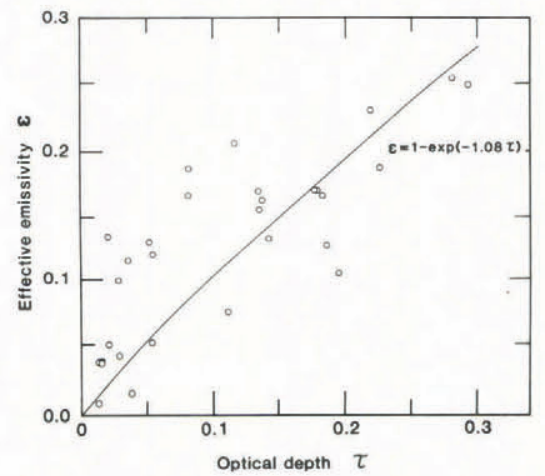

Fig.6. Longwave effective emissivity against shortwave optical depth of drifting snow.

wind speed are excluded and scattering of points becomes narrower compared with Figure 5 . The best fit curve shown in the figure by the solid line is

$$
\epsilon=1-\exp (-1.083 \cdot \tau)
$$

\section{EFFECTS ON TOTAL RADIATION BUDGET}

Due to drifting snow within a $30 \mathrm{~m}$ layer $(1.5-30$ $\mathrm{m})$, net longwave cooling will decrease at a rate of $2 \mathrm{~W}$ $\mathrm{m}^{-2} / \mathrm{m} \mathrm{s}^{-1}$ and global solar radiation will decrease at a rate of $1 \% / \mathrm{m} \mathrm{s}^{-1}$. Surface albedo, which is about $80 \%$, does not show any significant variation from drifting snow. Then, for total net radiation, effect of the longwave prevails when global radiation is less than $1000 \mathrm{~W} / \mathrm{m}^{2}$, which is never surpassed all the year round at Mizuho Station. Effects of drifting snow on the total radiation budget at Mizuho Station are roughly estiamted. In 1979, there were 105 days with the wind speed stronger than $12.5 \mathrm{~m} / \mathrm{s}$ and 162 days with drifting snow (VIS $<1 \mathrm{~km})$. As a monthly average, the largest contribution is seen in September. Net radiative cooling decreases about $3.2 \mathrm{~W} / \mathrm{m}^{2}$, which is $13 \%$ of the total net radiation.

\section{CONCLUSIONS}

At Mizuho station drifting snow acts to suppress the surface radiative cooling and enhances cooling of the atmospheric layer. This is owing to the strong effect of drifting snow on the longwave radiation. Drifting snow becomes effective when wind speed rises above 13 $\mathrm{m} / \mathrm{s}$. For the true surface the effect of drifting snow 
will be even greater, since the 'surface' measurements were made at the $1.5 \mathrm{~m}$ level.

\section{ACKNOWLEDGEMENTS}

The authors are indebted to $\operatorname{Dr} S$ Takahashi of Kitami Institute of Technology, and Drs S Kobayashi and $\mathrm{H}$ Nishimura, Institute of Low Temperature Science, Hokkaido University, for their kind advice on analysis of drifting snow amounts.

\section{REFERENCES}

Budd, W F, Dingle W R J, Radok U 1966 The Byrd snow drift project: outline and basic results. In Rubin M J (ed) Studies in Antarctic meteorology. Washington DC, American Geophysical Union; 71-134. (Antarctic Research Ser. 9)

Kawaguchi S 1979 Radiation properties of Antarctic atmosphere. Dr. Sci. thesis, Tohoku University 179p

Kobayashi S, Makino K 1975 A preliminary report on blowing snow observation using the light scattering in high winds at Syowa Station, Antarctica. Antarctic Record 53; 45-52

Kobayashi S, Ishikawa N, Ohata T 1983 Snow storm with strong wind in Antarctica. Low Temperature Science A, 42; 65-79

Mellor M 1966 Light scattering and particle aggregation in snow-storms. Journal of Glaciology 6 $237-248$

Paltridge G W, Platt C M R 1981 Aircraft measurements of solar and infrared radiation and the microphysics of cirrus cloud. Quarterly Journal of the Royal Meteorological Society 107: 367-380

Schmidt R A 1979 Measuring visibility in blowing snow. Snow removal and ice control research Spec. Rep. 185. National Academy of Science, Washington DC: 200-207

Stephens G L 1978 Radiation profiles in extended water clouds. II: Parameterization Schemes. Journal of Atmospheric Science 35: 2123-2132

Tabler R D 1979 Visibility in blowing snow and applications in traffic operations. Snow removal and ice control research Spec. Rep. 185. National Academy of Science, Washington DC: 208-214

Takahashi S 1985 Characteristics of drifting snow at Mizuho Station, Antarctica. Annals of Glaciology 6: $71-75$

Takahashi S, Ohmae $\mathrm{H}$, Ishikawa $\mathrm{M}$, Katsushima $\mathrm{T}$ and Nishio F 1984 Observation of snow drift flux at Mizuho Station, East Antarctica, 1982. Memoirs of the National Institute of Polar Research Special Issue 34: 113-121

Yamanouchi T 1983 Variation of incident solar flux and and snow albedo on the solar zenith angle and cloud cover, at Mizuho Station, Antarctica. Journal of the Meteorological Society of Japan 61: 879-893

Yamanouchi T, Kawaguchi S 1984 Longwave radiation balance under a strong surface inversion in the katabatic wind zone, Antarctica. Journal of Geophysical Research 89: 11771-11778

Yamanouchi T, Wada M, Mae S, Kawaguchi S, Tsukamura K 1981 Measurements of radiation components at Mizuho Station, East Antaretica in 1979. Memoirs of the National Institute of Polar Research Special Issue 19: 27-39 